\title{
UJI KADAR OKSIGEN PADA AIR MINUM KEMASAN DAN FAKTOR-FAKTOR YANG MEMPENGARUHI KANDUNGAN OKSIGEN TAHUN 2015
}

Ayu Pertiwi, Khambali, Rusmiati

\section{ABSTRACT}

Today, there are many oxygenated drinking water are sold in public. Information on labels mentions that they contain oxygen of 20 ppm to 100 ppm. There are several factors affect oxygen level; hence, actual measurement of the oxygen content in oxygenated drinking water was carried out. The purpose of this study is to determine oxygen level in oxygenated drinking water and determine factors that affect oxygen content.

This is a descriptive research. Data collection was carried out by measuring oxygen content in oxygenated drinking water. Samples was taken from pharmacy and super market at Surabaya, with four brands and by three repetitions. Data were then analyzed in by description.

Test results of oxygen content in oxygenated drinking water on sample $A$ showing that the original oxygen content is $5.26 \%$, oxygen content of sample $B$ was $13.78 \%$, sample $C$ was $3.62 \%$, and sample $D$ was $16.74 \%$. The four sample show that the oxygen content is lower than label statement.

Oxygen reduction in oxygenated water is influenced by several factors including temperature of storage. Producers are suggested to improve control quality of their products and government should supervise oxygenated drinking water to avoid public deception because information mentioned does not match reality.

Keywords: Oxygenated drinking water, oxygen content

\section{PENDAHULUAN}

Kelangkaan air bersih layak minum ini menginspirasi lahirnya produk air minum dalam kemasan. Saat ini banyak industri yang mengeluarkan produk air minum dengan ditambahkan oksigen. Dengan teknologi MReT (Molecular Resonance e-Magnetic Technology) dari Kanada dan teknologi dari Jerman,air yang semula biasa dirubah menjadi air beroksigen tinggi karena ditambahkan oksigen hingga mencapai 100 ppm perbotolnya (Anonim, 2013).

Dari hasil observasi pendahuluan didapatkan kandungan oksigen yang ada pada air minum kemasan beroksigen tidak sesuai dengan informasi di label kemasan. Diduga ada faktor lain yang mempengaruhi penurunan kadar oksigen tersebut. Karena kondisi tersebut, penulis mengadakan penelitian karya tulis ilmiah tentang oksigen dalam air minum kemasan dengan judul "UJI KADAR OKSIGEN PADA AIR MINUM DALAM KEMASAN DAN FAKTOR-FAKTOR YANG MEMPENGARUHI KANDUNGAN OKSIGEN TAHUN 2015".

\section{TUJUAN}

Tujuan Penelitian ini adalah mengukur kadar oksigen yang terkandung pada air minum dalam kemasan dan menganalisis faktorfaktor yang mempengaruhi menurunnya kadar oksigen dalam air minum kemasan.

\section{METODE PENELITIAN}

Jenis penelitian ini merupakan penelitian deskriptif yaitu penelitian yang menggambarkan berapa kadar oksigen yang terkandung pada air minum kemasan beroksigen dan faktor-faktor yang mempengaruhi penurunan kadar oksigen.

Populasi dalam penelitian ini adalah air minum kemasan yang dijual di supermarket maupun di apotek. Sampel dalam penelitian ini adalah air yang diambil dari beberapa air minum kemasan beroksigen. Teknik sampling yang digunakan dalam penelitian ini adalah dengan metode accidental sampling. Pengukuran data dengan cara mengukur kadar oksigen yang terkandung pada air minum dalam kemasan beroksigen tinggi. Analisis data yang digunakan pada penelitian dengan cara tabulasi data dan selanjutnya peneliti mendeskripsikan hasil dari data yang diperoleh (Soekijo, 2012). 


\section{HASIL DAN PEMBAHASAN}

Dari pemeriksaan laboratorium pada air minum kemasan beroksigen didapatkan hasil

Tabel I. 1

Hasil Pemeriksaan Oksigen Air Minum Kemasan Beroksigen sebagaimana tercantum dalam tabel I. 1 sebagai berikut:

\section{Kadar Oksigen Terlarut (Ppm)}

No $\quad \begin{gathered}\text { Kode } \\ \text { Sampel }\end{gathered} \begin{gathered}\text { Hasil Pemeriksaan } \\ \text { Oksigen Terlarut }\end{gathered}$
Oksigen Terlarut pada
Label Kemasan

\section{Persentase oksigen (\%)} penurunan kadar (Ppm)

\begin{tabular}{ccccc}
\hline 1. & A1 & 14,71 & 20 & 5,29 \\
\hline 2. & A2 & 14,74 & 20 & 5,26 \\
\hline 3. & A3 & 14,71 & 20 & 5,29 \\
\hline 4. & B1 & 36,22 & 50 & 13,78 \\
\hline 5. & B2 & 36,24 & 50 & 13,76 \\
\hline 6. & B3 & 36,22 & 50 & 13,78 \\
\hline 7. & C1 & 76,44 & 80 & 3,56 \\
\hline 8. & C2 & 76,41 & 80 & 3,59 \\
\hline 9. & C3 & 76,38 & 80 & 3,62 \\
\hline 10. & D1 & 83,26 & 100 & 16,74 \\
\hline 11. & D2 & 83,31 & 100 & 16,69 \\
\hline 12. & D3 & 83,29 & 100 & 16,71 \\
\hline
\end{tabular}

Sumber : Data Sekunder

Pada tabel I. 1 dapat diketahui kandungan oksigen pada seluruh sampel tidak sesuai dengan informasi yang tertera di dalam label produk. Hasil pemeriksaan menunjukkan kandungan oksigennya hanya berkisar 14,71 ppm sampai 83,31 ppm. Persentase penurunan yang paling rendah yaitu $5,26 \%$ dan persentase penurunan yang paling tinggi yaitu $16,74 \%$. Angka persentase penurunannya pada setiap sampel tidak sama dikarenakan penambahan oksigen yang disuntikkan ke dalam kemasan juga tidak sama. Semakin besar jumlah oksigen yang ditambahkan maka semakin besar oksigen yang dilepaskan.

Rata-rata suhu air minum kemasan beroksigen sebesar $29{ }^{\circ} \mathrm{C}$ ini melebihi kadar maksimum yang diperbolehkan sesuai dengan Peraturan Menteri Kesehatan Republik Indonesia Nomor 492 tahun 2010 tentang Persyaratan Kualitas Air Minum yaitu antara $10{ }^{\circ} \mathrm{C}-25{ }^{\circ} \mathrm{C}$ (sejuk). Dari seluruh sampel yang diperiksa, sampel kode D1, D2, dan D3 merupakan air minum kemasan beroksigen yang paling baik diantara merk lainnya. Faktor - faktor yang mempengaruhi penurunan oksigenyaitu :

1. Suhu

Apabila pada saat penyimpanan suhunya tinggi maka oksigen yang di dalam botol akan menurun, sedangkan apabila penyimpanan suhunya rendah maka oksigen akan naik. Sehingga hal ini bisa menyebabkan berkurangnya kadar oksigen. Jika oksigen sudah berkurang air kemasan beroksigen ini akan menjadi air biasa (Anonim, 2013). Oksigen terlarut dalam air berasaldari difusi udara dan hasil fotosintesis organismeberklorofil yang hidup dalam suatu perairan dandibutuhkan oleh organisme untuk mengoksidasi zathara yang masuk ke dalam tubuhnya (Nybakken, 1988 dalam Marojahan, 2007). Kekurangan oksigen dapat menyebabkan metabolisme berlangsung tidak sempurna (Nikmawati, Ellis Endang, 2010). Oleh karena itu seharusnya penyimpanan dilakukan pada suhu yang rendah agar kandungan oksigennya tetap stabil.Perlu pengawasan dari perusahaan terhadap produk yang sudah didistribusikan, karena jika tidak dilakukan monitoring bisa jadi produk ini tidak sesuai dengan peruntukannya.

2. Proses produksi

Dalam proses pembuatan air kemasan beroksigen, salah satunya yaitu terdapat proses bottling and filling. Pada proses produksi hal yang memungkinkan beresiko berpengaruh terhadap penurunan oksigen yaitu terletak pada saat bottling and filling. Apabila tutup botol tidak rapat maka 
oksigen yang di dalam botol akan merembes keluar. Hal ini diperlukan bahan tutup botol yang kedap udara serta tidak mudah lubang dan sobek.Serta perlu kekuatan dan keakuratan mesin saat mengepress tutup botol ke lubang mulut botol kemasan. Diharapkan tidak bocor dan tidak merusak botol kemasan.Kemasan air oksigen juga perlu diperhatikan. Kemasannya harus sangat baik dan kedap udara supaya oksigen yang sudah ada dalam air tidak tembus keluar lewat kemasan. Pori-pori plastik kemasan juga harus sangat harus. Telah diketahui bahwa oksigen merupakan gas dan gas bisa saja menembus dan menempati ruang yang kosong (Anonim, 2013).

3. Membuka tutup botol terlalu lama

Dengan ditambahkannya oksigen secara paksa ke dalam botol air minum kemasan, maka tidak baik membuka tutup botol terlalu lama karena oksigen yang sudah dimasukkan ke dalam kemasan akan bebas kembali ke udara.

4. Tempat penyimpanan

Di super market dan apotek air minum kemasan beroksigen ini belum semuanya diletakkan pada tempat yang sesuai.Air minum beroksigen lebih baik diletakkan dan disimpan di tempat yang sejuk, sesuai dengan suhu air yang berkisar antara $10{ }^{0} \mathrm{C}-25{ }^{\circ} \mathrm{C}$. Sedangkan menurut Keputusan Menteri Kesehatan Nomor 1405 tahun 2002 tentang Pesyaratan Kesehatan Lingkungan Kerja Perkantoran dan Industri persyaratan udara ruangan yang diperbolehkan yaitu ruangan mempunyai suhu $18{ }^{\circ} \mathrm{C}-28{ }^{\circ} \mathrm{C}$ dan memiliki tingkat kelembaban $40 \%$ $60 \%$. Jadi, apabila tempat penyimpanan air minum kemasan beroksigen ini melebihi dari suhu yang sudah ditentukan, maka akan mempengaruhi kandungan oksigen. Pihak pengelola seharusnya melakukan upaya menjaga suhu ruangan sama seperti suhu air yaitu dengan cara menambahkan alat pendingin. Penyimpanan minuman yang diletakkan pada rak harus memenuhi persyaratan, yaitu jarak antara minuman yang paling bawah dengan permukaan lantai minimal $15-25 \mathrm{~cm}$, sedangkan jarak minuman yang paling atas dengan langit-langit minimal $60 \mathrm{~cm}$, dan jarak antara minuman dengan dinding minimal $5 \mathrm{~cm}$ ( Suharyati, 2014).

\section{KESIMPULAN}

1. Hasil pemeriksaan oksigen terlarut yang dilakukan di Laboratorium Terpadu Poltekkes Kemenkas Surabaya, menunjukkan bahwa kandungan oksigen pada masing-masing sampel hanya berkisar 14,71 ppm hingga 83,31 ppm. Angka penurunan oksigen pada masingmasing sampel berbeda-beda. Ada yang mengalami penurunan sebesar 3,56\% hingga mencapai $16,74 \%$ dari total kadar oksigen yang tercantum pada label kemasan produk.

2. Faktor - faktor yang mempengaruhi penurunan kandungan oksigen yaitu suhu, tempat penyimpanan, lamanya tutup botol dibuka, dan pada saat produksi.

\section{SARAN}

1. Bagi pelaku usaha atau perusahaan Perusahaan seharusnya lebih meningkatkan quality control pada produk yang dihasilkan. Pihak produsen harus memberi masukan untuk membekukan air minum dalam oksigen tersebut secara berlebih agar pada saat air tersebut dikonsumsi, penyusutan oksigennya tidak terlalu tinggi dan masih dalam kadar oksigen yang stabil.

2. Bagi pemerintah

Pemerintah sebaiknya melakukan pengawasan terhadap produk air minum kemasan beroksigen ini untuk mencegah pembohongan publik.

3. Bagi masyarakat

Sebaiknya ada informasi bagi masyarakat dari pihak produsen tentang bagaimana menyimpan produk air minum dalam kemasan beroksigen di rumah yaitu disimpan pada tempat pendingin dengan suhu berlebih untuk menjaga kadar oksigen agar tetap stabil.

4. Bagi peneliti

Bagi penelitian yang akan datang sebaiknya sampel dikelompokkan berbeda yaitu sampel yang dijual di super market atau apotek berdasarkan prinsip FIFO (first in first out) dan menguji kadar oksigen dengan perbedaan lamanya tutup botol dibuka. Peneliti berharap penelitian yang akan datang agar lebih sempurna daripada sebelumnya.

\section{DAFTAR PUSTAKA}

Arsyadin, dkk. 2012. Pengaruh Jarak Tempuh Air Dari Unit Pengolahan Air Terhadap Suhu, Ph, Kadar Sisa Klor Dan Angka Lempeng Total Bakteri Pada PDAM Kota Bima Nusa Tenggara. Analis Kesehatan Sains Vol 01. No. 
02.2012 ISSN 2302-3635. Jurusan Analis Kesehatan Poltekkes Sby.

Asmadi.,Khayan., Kasjono, Heru Subaris, 2011. Teknologi Pengolahan Air Minum.Yogyakarta, Gosyen Publishing.

Budiono dan Sumardiono, Siswo. 2013.

Teknik Pengolahan Air. Yogyakarta:

Graha Ilmu.

Hanafi, Imam. 2011. Kebijakan Air Bersih. Malang. UB Press.

Joko, Tri. 2010. Unit Produksi dalam Sistem Penyediaan Air Minum. Yogyakarta. Graha Ilmu.

Kusnaedi, 2010. Mengolah Air Kotor untuk Air Minum. Jakarta: Penebar Swadaya.

Margono.2010, Penyediaan Air Bersih.Surabaya, jurusan Kesehatan Lingkungan. Buku Ajar Jilid 1: 6.
Notoatmodjo, Soekidjo, 2012. Metodologi Penelitian Kesehatan. Jakarta, Rineka Cipta.

Peraturan Menteri Kesehatan Republik Indonesia Nomor 173 Tahun 1977 Tentang Pencemaran Air Dari Badan Air Untuk Berbagai Kegunaan Yang Berhubungan Dengan Kesehatan.

Santoso,Yudi. 2010. Keajaiban Oksigen untuk Kesehatan. Yogyakarta: Palmall.

Subchan, W. 2010. IImu Pengetahuan Lingkungan. Jember: Jember University Press.

Sumirat, Juli. 2011. Kesehatan Lingkungan. Jakarta. Penerbit Gadjah Mada University Press.

Sutrisno, Totok. 2010. Teknologi Penyediaan Air Bersih. Jakarta. Rineka Cipta. 